\title{
EL EXTRAVÍO DE REALIDAD BASADO EN EL DESFALLECIMIENTO DE LOS SÍMBOLOS
}

The lost reality rooted on the fallen of symbols

\author{
José Barrientos Rastrojo*
}

Resumen

Este trabajo pretende analizar la pérdida del símbolo en la actualidad dialogando con las bases de la hermenéutica y de la filosofía de la cultura. Seguidamente, expondrá el paso del sentido ontológico al pragmático del símbolo. Finalmente, propondrá una vía para su recuperación, centrándose en la figura de la palabra y en la necesidad de rescatar su verdad diciente y aletheica, esto es, (1) defendiendo que la verdad es más que "adequatio" entre la cosa (res) y el intelecto y (2) recuperando las fuentes sagradas del ente y de la palabra.

Palabras clave: símbolo, hermenéutica, experiencia, palabra, ontología.

Abstract

This paper aims to analyze the loss of the symbol today, by means of a dialogue on the foundations of hermeneutics and philosophy of culture. Then, it will expose the transfer from an ontological to a pragmatic sense of symbol. Finally, it will propose a path to recuperation, by focusing on the figure of the word and the need to rescue its aletheica, that is, (1) by defending that the truth is more than 'adequatio' between the thing (res ) and intellect and (2) by recovering the sacred sources of body and word.

Key words: symbol, hermeneutics, experience, word, ontology.

\section{PLANTEAMIENTO DEL PROBLEMA: ¿ESTAMOS PERDIENDO SÍMBOLO Y REALIDAD?}

\section{I.A. INTRODUCCIÓN}

La filosofía de la religión enmarca histórica y ontológica el símbolo en la tradición del concepto. Este, el rito, el mito y la mística han puesto en contacto al creyente con los misterios de lo real, así como nos han explicado con maestría autores como Mircea Eliade, ciertos teólogos y la patrística. No obstante, estas disciplinas no son las únicas que han indagados en esta categoría.

La hermenéutica, de la mano del filósofo mexicano Mauricio Beuchot, ha profundizado en la idea: en la medida en que el símbolo exige una interpretación que requiere una técnica específica, la ciencia de la comprensión filosófica supone un excelente "mistagogo" para comprender los secretos que guardan sus entrañas.

Ricoeur, maestro de Beuchot, se une a los desvelos del mexicano. De acuerdo con Finitud y culpabilidad, comprender la entraña de nuestro tema exige orientarse en 


\section{José Barrientos Rastrojo}

una dirección específica respecto del lenguaje y posicionarse a uno mismo en una determinada línea de clarificación (Ricoeur, 2004, p. 484-490).

Ernst Cassirer (1967) forja una antropología cultural basada en el símbolo. De modo concreto: lo simbólico incursiona en los universos que trascienden las dimensiones visibles y físicas, a saber, el arte, la ciencia, el mito y el lenguaje. Todos estos orbes promueven la auténtica naturaleza humana, por lo que su abandono conduce a su involución (Conill, 1991, p. 48-49, 54-55, 106-123).

La teoría sociológico-lingüística de Norbert Elías circunscribe nuestro tema al concepto pronunciado en la palabra articulada oralmente. La palabra implica la esencia jánica compuesta por un significante físico (expuesto por el significante fonemático) y un vuelo trascendente (el significado); así, la palabra "luna", "moon" o "lua" (significante) apunta un objeto físico con la que se une por razones contextuales (Elías, 1994, p. 35-36).

Estos cinco autores (Eliade, Beuchot, Ricoeur, Cassirer y Elias) nos ayudarán para comprender la naturaleza de nuestro tema de investigación. La elección del quinteto se basa en que ellos representan las principales vías de estudio contemporáneo del símbolo: mítico-religiosa, hermenéutica, antropológica y lingüística. Por otra parte, resumen los juicios más destacados en relación con la pregunta en la que descansa nuestro trabajo: "¿se están perdiendo los símbolos en la contemporaneidad?"

En síntesis, este trabajo (1) expondrá la disquisición acerca de la pérdida del símbolo, (2) avanzará en el discernimiento acerca de su contenido sobre la base de las diversas teorías y (3) concluirá con una respuesta a la desaparición/desplazamiento simbólico en tres niveles: entes, tiempos y espacios simbólicos.

\section{I.B. PÉRDIDA DEL SÍMBOLO SEGÚN BEUCHOT Y ZAMBRANO}

Según Mauricio Beuchot y María Zambrano, el símbolo, el rito, los dioses y el mito pierden o devalúan su carta de autonomía en la modernidad y en la contemporaneidad bajo los auspicios de la racionalidad pragmatista y del positivismo tecnológico reductor de significados.

Estamos en un tiempo indigente, como decían Hölderlin y Heidegger, refiriéndose a la pérdida de los dioses, pero ahora refiriéndonos a los símbolos. $\mathrm{Y}$ es que los dioses acostumbraron a hablar en símbolos. $\mathrm{Y}$ ahora han enmudecido (Beuchot, 2011, p. 49).

El silencio se materializa desde los dos sentidos posibles: objeto (la ausencia de voz del símbolo) y sujeto (la clausura de los sentidos del oyente, es decir, la suspensión de las capacidades intuitivas de la persona para comprender la entraña de su misterio). Esto último no responde a una minusvalía psicológica sino epistémica: se ha "corroído" el "a priori de la simbolización" (Beuchot, 2007, p. 13), es decir, se ha quebrado el marco que permite la aprehensión. Si Kant apelaba al espacio y el 
tiempo como a priori epistemológicos, Beuchot aplica estas entidades a la interrelación de sujeto y símbolo y, sobre su base, explica la menesterosidad que incapacita para entrar en contacto con el símbolo.

Los símbolos aparecen "rotos" y "caídos" (Beuchot, 2007: 13). Esta ruptura apela a la destrucción de la integridad dicotómica que compone este ente: las dimensiones metonímicas y metafóricas. La metonimia del símbolo se instala en la parte física del objeto (el significante); la metafórica alude al trascendental (el/los significado/s). La caída los hace descender a su componente metonímico. Por ello, su pérdida nos hurta el vuelo, nos impide "atisbar, avizorar y entrever una trascendencia" (Beuchot, 2011, p. 49) y nos incardina en una asfixiante inmanencia que puede llegar a ser patológica (Durand, 1968, p. 75).

María Zambrano ha concluido en este magma común en varias obras. Según la pensadora española que se afincó algún tiempo en Morelia (Michoacán), nos encontramos "desnudos de mitología, ávidos de visión, visionarios en ayunas en pleno eclipse de las religiones habidas" (Zambrano, 2004, p. 79).

Originariamente se sucedieron dos escenarios que representan dos modos de afrontamiento del mundo. El primero es afin al poeta, un sujeto embriagado por los poderes misteriosos, místicos y simbólicos de la vida, esto es, sumido por lo óntico. Los dioses, y la realidad en general, le interpelan. Se comunica con la naturaleza palpitante porque en este orbe básico no se ha operado la escisión entre el sujeto y el objeto. El poeta se siente mero medio de transmisión y la naturaleza toma su voz para expresarse. Su ser vincula íntimamente con los misterios de la naturaleza que canta al verse rodeado y perseguido por ellos. Estos hombres sentían el "delirio persecutorio" de los dioses, de lo sagrado (Zambrano, 1993, p. 31; Marí, 1988, p. 74). El símbolo en este contexto conforma una instancia básica, pues no se entiende el significante sin instancias más profundas o más trascendentales: la tormenta resulta de castigos divinos, el nacimiento de un niño manifiesta el beneplácito de instancias ocultas, las estaciones del año quedan signadas por referencias que superar la cronología con un ascenso hacia lo kairótico y la enfermedad se vincula con influencias anímicas y espirituales más que con la metonimia de razones biológicas.

En el segundo escenario zambraniano, el poeta se distancia de la realidad y se crea el clásico binomio epistémico entre sujeto y objeto: asistimos a la época de la razón lógico-argumental. Aunque la inmersión del individuo en lo que le circunda se lesiona, se percibe un beneficio obvio: la liberación del caos y de la incertidumbre de la que dependía el poeta. Este provecho procede de la comprensión de los resortes de la vida y de la utilización del saber resultante con fines pragmáticos. Este argumentado experimenta una "liberación previa de la ignorancia total", "del círculo mágico de la ignorancia y de la servidumbre", si bien contiene una contrapartida: la pérdida del "encantamiento" producido por los dioses y por la vida latiente (y simbólica) (Zambrano, 1956, p. 558). 


\section{José Barrientos Rastrojo}

La perspectiva lógico-argumental no es problemática en la medida en que acepte la coralidad de interpretaciones; sin embargo, la modernidad y la contemporaneidad implican el ensoberbecimiento de un positivismo que orilla las visiones poéticas. Lemas como los siguientes explicitan esta circunstancia: "la poesía no es solo error, es una mentira inventada creada voluntariamente" (Zambrano, s/f-a, p. 4), "lo que no responde a la razón es mito, engaño adormecedor; sombra de una sombra moviéndose sin despejarse de la pétrea parada de la caverna" (p. 10).

Esta perspectiva se inserta y concuerda con la aproximación heideggeriana cuando el alemán explica el olvido del ser y la dilapidación de los sentidos de lo real. En la contemporaneidad, el único sentido legitimado es el pragmatista, esto es, aquel que impone el interés utilitarista del sujeto. De esta forma, se silencia la auténtica propia del ente, es decir, aquella que florece de su propia entraña. Caminos del bosque ejemplifica esa situación exponiendo dos abordajes diferentes relativos a las botas de campesino: el labriego y el pintor. Desde la óptica utilitarista del agricultor, las botas son aquello que sirve para proteger los propios pies de los afanes del día a día y para facilitar el quehacer en el huerto: "Las botas campesinas las lleva la labradora cuando trabaja en el campo y solo en ese momento son precisamente lo que son. Lo son tanto más cuanto menos piensa la labradora en sus botas durante su trabajo, cuando ni siquiera las mira ni las siente" (Zambrano, s/f-a, p. 23). El trabajador se detiene a pensar en ellas cuando surge algún problema en su entidad funcional. Así, el ser del calzado se yergue como el máximo nihilismo, quedando ocultada su esencia por una perspectiva sesgada y falsa de ellas mismas. El artista, representado en esta obra por Van Gogh, devuelve a las botas su esencia. La pintura "Par de botas" alza su tema al permitir la apertura de sentidos desde sí mismas. Van Gogh no utiliza las botas para sus quehaceres cotidianos sino que se deja calzar por ellas para que se abran a su multiplicidad significativa en el retrato. La pintura de las botas no explica su sentido a partir de los intereses de un sujeto sino que exige al espectador que claudique su yo y permanezca a la escucha de la apertura de la entraña de las botas. Así, el/los sentido/s de los zapatos emergen de ellas mismas.

Por otra parte, la clarificación del significado de las botas por este medio las alza más allá de la inmanencia reducida de esas ser "estas" o "aquellas" botas. Su naturaleza queda patentizada como paradigma que define la entraña de cualquier tipo de botas de labriego en el sentido expuesto por Cassirer en su Filosofia de las formas simbólicas. Después de que esta pintura se implante como modelo ontológico-artístico, todo aquel calzado que aspire a convertirse en unas botas de campo habrá de aspirar al modelo de Van Gogh. Aquí se patentiza una conexión nodal con el símbolo: la pintura posee una conexión metonímica (el lienzo pintado) y una metafórica (la forma arquetípica a la que apunta). Sin la segunda, el arte queda reducido o devaluado. El lienzo del autor holandés es arte y no un mero dibujo porque ha alcanzado la forma simbólica trascendental, ha bosquejado una modulación específica de la verdad. 
El segundo ejemplo heideggeriano que critica el exilio de la policromía hermenéutica se cita en los siguientes términos "El metal siente añoranza. Y quiere abandonar las monedas y ruedas, que le enseñan una vida pequeña" (Cassirer, 1971, p. 217). Como en el caso de las botas, el metal trasciende la semántica de la utilidad acuñada por el ser humano. Su ser como monedas o como ruedas es la perversión raquítica de su auténtica semántica; de hecho, esta circunstancia la conmina a una "vida pequeña" o mutilada porque quedan atrás el resto de sus potencialidades. La grandeza del metal podría evidenciarse en el poema o en la obra pictórica como en el caso de Van Gogh.

Los ejemplos podrían multiplicarse: el contraste del río para el molinero y para el poeta, las concepciones del árbol para el carpintero y de aquel olmo viejo cantado por Machado (1997, p. 46-47), etcétera. En todos los casos, la realidad se dignifica en las manos del artista. Su dignidad se aloja en la verdad que pueden inaugurar. Esa verdad recapacita al sujeto para ver, como indica Heidegger (2001): "ha sido la obra de arte la que nos ha hecho saber lo que es de verdad un zapato" (p. 23). Así, si volvemos a anudar esta reflexión al símbolo, obtenemos una posible vía de las capacidades apriorísticas que permiten la aprensión del símbolo y que fueron robadas en el pasado.

La pérdida del símbolo responde al esquema expuesto: la modernidad degrada el objeto a una naturaleza metonímico-pragmática, restringiéndolo a su valor de uso e impidiéndole liberar su potencialidad ontológica. Esto implica consecuencias con resultados visibles hoy: si la médula de un objeto reside en su utilidad, este será intercambiable por otro que cumpla la misma misión. Si el valor de un libro reside en su función para equilibrar una mesa inestable, este es intercambiable por un trozo de madera o cualquier otro objetivo que colme tal misión. Sin embargo, imaginemos que ese libro es un incunable que posee varios siglos, que es el último ejemplar en el mundo del Quijote o bien que estamos ante la cartilla con la que nuestra madre, recientemente fallecida, nos enseñó a leer. El hijo de esa madre o un filólogo nunca utilizará ese libro para estabilizar la mesa, porque es consciente de una inherencia mucho más amplia, de un sentido que se abre desde sí mismo.

Obviamente, el precio, entendido como síntoma del valor del objeto, desembolsado por quien lo usa bajo la pata y por quien lo tuvo en su infancia junto a su madre será muy diferente porque su valor cambia debido a que la potencialidad hermenéutica es diversa. Algunos críticos podrían decir que son dos semánticas igualmente válidas; sin embargo, ¿es así?, ¿acaso no es más sí mismo el libro cuando se le valora desde su exclusividad ontológica irrepetible que cuando se equipara a otros entes con los que se puede intercambiar? Ocultar o cegarse a la naturaleza del libro desde su forma inherente es robarle su ser y destruir parte de la realidad.

Es más, como en el caso del Par de botas de Van Gogh, el Quijote es el arquetipo simbólico que narra un modelo específico del ser. Perder esa obra de arte incapacita al sujeto a comprender ese modelo trascendental. 


\section{José Barrientos Rastrojo}

La modernidad se identifica con la época de la ciencia pragmática, del avance de su aireado pragmatismo y de la clausura de los sentidos metafóricos indicados a favor de los metonímicos signos anoréxicos. Por ello, tanto para Durand (1968, p. 2446) como para Beuchot (2007) "la modernidad fue el triunfo de la 'iconoclastia', de los iconoclastas o destructores de íconos, de símbolos, y el triunfo del mero signo" ( $\mathrm{p}$. 22). Según el mexicano, se constata el avance del nihilismo, ya que el símbolo (y la realidad en general) se vacía de las dimensiones trascendentes.

\section{I.C. EL DILEMA SIMBÓLICO: BEUCHOT FRENTE A ELIADE}

El aciago horizonte de Beuchot no coincide con el de Mircea Eliade. Si las aseveraciones previas fueran reales, ¿no habrían de reducirse los estudios de Filosofía de la Religión de Eliade a literatura desasistida de verdad o a estudios de entidades pasadas periclitadas? Por el contrario, el autor de Historia de las creencias y las ideas religiosas encuadra entre los entes simbólicos a realidades con manifiesta pujanza en la actualidad (el cine, la música o la literatura de ficción). De ello, infiere la negativa a su desaparición

Los símbolos nunca desaparecem da atualidade psíquica: podem mudar de aspeto mas a sua função continua a ser a mesma: basta retirar-lhes as suas novas máscaras. A mais abjeta "nostalgia" oculta a "nostalgia do paraíso". Fez-se referência às imagens do 'paraíso oceaniano' que povoam livros e filmes (Alguém disse já que o cinema era urna "fábrica de sonhos"). Também se pode de igual modo analisar as imagens subitamente libertadas por qualquer tipo de música, por vezes até pela mais banal romanza (Eliade, 1979, p. 17).

Aunque el modelo eliadiano es análogo al establecido arriba (la nostalgia de lo perdido se revive por medio de los símbolos citados), se ponen de manifiesto diferencias que van más allá de la defensa de que los símbolos mantienen su vitalidad, a saber, su palpitante dinamismo resulta de que el ser humano posee una necesidad ontológica y psicológica de vivir con el símbolo. Incluso en las trincheras de Estalingrado y en los campos de concentración nazis y soviéticos, la gente sacrificó parte de su comida para escuchar romanzas e historias (Eliade, 1979, p. 20-21).

Equiparar al símbolo con canciones, argumentos fílmicos o narraciones legendarias no implica que cualquier canción o película se convierta, eo ipso, en un símbolo. Se han de cumplir ciertos requisitos, del que destacamos que "un mito relata acontecimientos que tienen lugar in principio, esto es, en los inicios, en un instante primordial e intemporal, en un lapso de tiempo sagrado" (p. 56).

En suma, Mauricio Beuchot y Durand se asientan en la iconoclasia y Eliade en el desplazamiento simbólico. Si el primero avisa de la desaparición paulatina de los símbolos, el segundo indica un mero desplazamiento del objeto contenedor del símbolo.

La postura ante esta disquisición puede ser triple: el extravío simbólico, el desplazamiento a nuevos entes simbólicos o la inconmensurabilidad de las 
posiciones. La inconmensurabilidad permitiría que las dos perspectivas fueran válidas basándonos en que ambos apuntarían a contenidos diferentes para el término "símbolo". Este quehacer nos obliga a aproximarnos a las notas básicas de nuestro tema desde aproximaciones disciplinares politeístas que nos ayuden a armar una perspectiva cabal de su esencia. Esta multidisciplinariedad partirá de las visiones contemporáneas siguientes: la sociológico-lingüística de Norbert Elías, la antropológico-cultural de Ernst Cassirer, la analógico-hermenéutica de Beuchot, la místico-religiosa de Eliade y la ontológico-hermenéutica de Ricoeur.

\section{LOS PERFILES SIMBÓLICOS}

\section{II.A. LAS DOS CARAS DEL SÍMBOLO}

La característica en que concuerdan todos los teóricos del símbolo es su naturaleza jánica, su doble faz (Beuchot, 1999), diferenciándose sus abordajes por el tipo de parentesco que mantienen los dos elementos del binomio y el ente en que se produce.

Algunos autores, como el sociólogo Norberto Elías (1994), avanzan una relación arbitraria o contextual (p. 36, 82). El símbolo se identificaría con la expresión oral de una palabra que apelaría a un contenido que trasciende el sonido articulado. El cambio entre lenguas implica que un mismo contenido, por ejemplo la "luna", presente diversos significantes, "moon", "lua", "mond", "lune", "ilargia" o "manen". Elías incardina al símbolo dentro del lenguaje. Asimismo, despeja la duda de si el origen del aprendizaje lingüístico es biológico (ontológico) o cultural (otras dos caras metonímicas y metafóricas, respectivamente) al señalar que el aprendizaje de la lengua requiere ambos factores: una edad determinada para el aprendizaje y un contexto específico que capacite al niño para dar los primeros pasos. La capacitación no es posible allende una edad infantil, como demuestran los niños salvajes encontrados en el Romanticismo, ni más allá de una influencia social precisa, como demuestra la incapacidad del ser humano para hablar en las tribus de neanderthales.

El símbolo amplía su figura bajo la concepción de Cassirer. Los símbolos se materializan en aquellas instancias que permiten una elevación de la persona, a saber, el lenguaje, el arte, el mito y la ciencia. A diferencia del animal, el ser humano puede escapar de su inmanencia: el alimento es más que un satisfactor de necesidades básicas, un lienzo es más que una lona de tela en la que se impregnan pigmentos y la palabra no se incardina en modelos guturales dependientes de un aquí y un ahora sino que, como ya indicó Elías, permite describir el pasado y construir el futuro. Si en el animal las palabras son operadores dirigidos a fines en un hic et nunc, en el ser humano se describen designadores, esto es, términos con un significado que despegan (Elías, 1994, p. 32). Esta descripción posee incidencias antropológicas de relieve, subrayadas por Jesús Conil: la destrucción del magma simbólico conduciría a la des-realización del ser humano (54-55), porque los orbes simbólicos son los que fraguan la naturaleza del ser humano. La persona es el único ser que se ha de conquistar a sí misma para alcanzar su 


\section{José Barrientos Rastrojo}

ser, su esencia no le está dada de forma natural y el universo desde el que lo captura es el símbolo. Un animal no puede dejar de ladrar, pero si una persona se limita a repetir sonidos guturales durante toda su vida no es posible afirmar que estamos ante un ser humano, ya que no ha desarrollado aquello que le es inherente, a saber: el arte, el lenguaje, el mito y la ciencia o el pensamiento abstracto. Beuchot lo explicita con elocuencia en los siguientes términos:

El hombre, en su estado de yecto, no solo se encuentra como pro-yecto, sino como con-yecto, como conjetura que se lanza conjuntamente con las demás, como símbolo, como algo que está caído y solo puede ser levantado y elevado por algo que realice el ascenso (ascesis, ascesis). El símbolo es entonces lo que puede levantar al hombre de su postración, de su estado de yecto, para que no caiga en ser algo ab-yecto. Pero tiene que oír al símbolo, y oír al Ser en el símbolo, abandonar su estado de sórdido, de sordera para la simbolicidad (Beuchot, 2007, p. 19)

Esa elevación requiere aspirar a una entidad que lo supere, que trascienda las limitaciones espacio-temporales, que se convierta en un paradigma que le interpele. Estas características son propias de los símbolos y, por eso, el símbolo salva a la persona de su carácter metonímico animalizado (estado de yecto) y lo eleva proyectualmente.

\section{II.B. SÍMBOLO Y TRASCENDENCIA}

Decidir respecto de la permanencia de los símbolos hoy implica conocer el debate acerca de si su contenido se puede expresar mediante el lenguaje o este resulta insuficiente, es decir, si el símbolo se puede explicar o ha de vivirse. Los planteamientos responden a tres modelos.

Raimon Panikkar, Mircea Eliade o Gilbert Durand sugieren que siempre hay más en el símbolo de aquello que las palabras puedan exponer (Eliade, 1979, p. 18; Panikkar, 2001, p. 36), supone una "epifanía por el significante", es decir, su contenido sale de sí mismo sin posibilidad de que una explicación pueda alcanzar toda su riqueza (Durand, 1968, p. 13-14). Debido a que convoca la realidad profunda "de la vida y del alma", sería complejo que todo su cromatismo pueda ser trazado desde los pinceles de los términos de unos u otros idiomas (Eliade, 1979, p. 21). Es preciso vivir el símbolo para comprender su contenido.

Mauricio Beuchot es consciente de la profundidad del símbolo y de que la esencia del concepto es definición, esto es, la delimitación de su contenido en un marco específico. El símbolo pertenecería a la vida e intentar acaparar esta en la red de la palabra es una tarea hercúlea o utópica. A pesar de ello, se podría ofrece una explicación "suficiente" del contenido del símbolo. La amplitud no impide que se puedan proyectar acercamientos comprensivos al símbolo. Concordamos, aquí, con Beuchot, porque el quehacer de Eliade en su obra es la explicación de esos símbolos (Eliade, 1968, 1996, 2010, 2011a y 2011b). Por ello, su teoría no tiene sentido a la luz de sus escritos. Eliade 
(1979) explica el símbolo del centro, el del árbol, el del agua, el de lo femenino (p. 27173) y, aunque no alcance toda la vitalidad de su entraña, nos acerca a ella. A pesar de esto, mostramos cierta incomodidad con el término usado por el mexicano: no consideramos que la interpretación simbólica sea "suficiente" sino que, a lo sumo, es "posible" (y "necesaria" en un contexto racionalista).

Por una parte, asumimos la insuficiencia de la explicación en la medida en que queda demasiada realidad allende la hermenéutica descrita en los libros para indicar que es suficiente. Ahora bien, la interpretación es posible porque puede hablarse sobre el símbolo. Aun en este punto hay que distinguir entre hablar sobre y desde el mismo.

Ricoeur matiza este punto creando una postura intermedia profunda. Según Finitud y culpabilidad, Eliade habría desarrollado sus investigaciones dentro del símbolo, es decir, se habría limitado a describir los símbolos (o a recrearlos) aceptando una función especular y no reflexiva (Ricoeur, 2004, p. 487), los habría cantado "desde dentro" (488). Esta acción pretende capturar su esencia sin imponerle sentido alguno. Esta lectura ayuda al lector a disponerse en la dinámica simbólica, aquella que "pertenece al movimiento que se dirige al punto de partida" (482). Esta misión respeta la labor de nuestro concepto: interpelar al sujeto (483) y no solo describir una realidad. Situarse en el plano descriptivo para narrar el símbolo de modo objetivo no es el camino: hay que trasladarse del "mito-explicación" al "mito símbolo" (484). El problema para Ricoeur es análogo al del Hyperion de Hölderlin: ¿cómo recuperar esa localización originaria hoy en relación con el símbolo? De acuerdo con el filósofo francés, se puede salvar esta geografía interpretando, abandonando "el exilio del espectador distante y desinteresado" (487) y articulando una implicación que no solo se disuelva en la inmersión de Eliade sino que capture la ontología del hecho con una nueva síntesis. Hoy, no es posible reintroducirnos en el pasado originario, lo que no impide re-crear lo originario en un presente. La "apuesta" será el mistagogo que ayude en este desafío:

Apuesto que comprenderé mejor al hombre y la relación entre el ser del hombre y el ser de todos los entes, si sigo la indicación del pensamiento simbólico. Esta apuesta se convierte entonces en la tarea de comprobar mi apuesta y de saturarla de inteligibilidad en cierto modo (...), al apostar por la significación del mundo simbólico, apuesto al mismo tiempo que recuperaré mi apuesta en forma de poder de reflexión, dentro del elemento de un discurso coherente (488).

Así, la re-aprehensión del momento originario depende, por una parte, de una saturación de sentidos y de la dotación de pasión a cada uno de esos sentidos, es decir, apostar y creer en un conjunto de significados y, por otro lado, es precisa la estructuración del contenido de modo coherente, lo que, estimamos, responde a la asunción de Ricoeur en la necesidad epistémico-formal de la ontología en el ser humanos, es decir, la asunción de que la interpretación en el ser humano depende de la captación de "un discurso coherente". La diferencia con Panikkar o Eliade es de base: la diferencia de los modelos antropológicos. Para los últimos, se asume un ser 


\section{José Barrientos Rastrojo}

humano que puede entrar en contacto directo con el símbolo y cuya comprensión no requiere explicación analítica, mientras que el francés no abandona el arraigo moderno que exige una comprensión racional de cualquier objeto hermeneutizable.

\section{II.C. SÍMBOLO Y UNIDAD E IDENTIDAD SOCIAL}

Beuchot (2007) contrapone el sym-bolo al dia-bolo (p. 47). El primero se caracteriza por su potencialidad para unir lo lanzado de forma independiente, esto es, las dos esferas del símbolo aludidas arriba, y el diábolo, o diablo, las separaría.

El símbolo no solo reúne a sus componentes sino que reúne a los seres en torno a sí. En el imaginario beuchotiano, esto es consecuencia de las categorías afectivas que le son consustanciales: el símbolo "está cargado de afecto, es un signo que vincula, que une" (Beuchot, 2007, p. 9); "es, sobre todo lo que lo vincula con su grupo, lo que más le da sentido de pertenencia, pues compartir los símbolos es más unidos que cualquier otra cosa (...) lo que lo ata afectivamente a los demás" (13). Por tanto, es un principio de unidad y de identidad. La bandera, un libro sagrado, los exvotos de la fundadora de una orden, ciertos ritos dentro de una familia o una sociedad, el cumplimiento de los tiempos sagrados en una comunidad no solo recuerdan un pasado sino que materializan una vinculación en el presente y una sensación de pertenencia al grupo (al ejército, a una religión o a los hijos, padres o hermanos). La unidad imprime carácter en los individuos, por lo que el símbolo vehicula respuestas para la pregunta identitaria "¿quién soy?" y "ayuda a conservar la identidad de los pueblos" (Beuchot, 2004b, p. 79).

El lenguaje o la cultura ejemplifican esta singularidad. Para Elías (1994) el uso del lenguaje requiere una comunidad que comparta los símbolos lingüísticos (p. 50, 71). Estos grupos no solo se establecen entre los habitantes de una nación que comparten la misma lengua oficial sino entre los profesionales unidos por una terminología específica opaca a otras disciplinas. Así, el lenguaje crea preguntas y marca líneas de respuesta. Por ejemplo, las razones que explican una enfermedad son diversas entre un grupo de médicos de familias del siglo XXI, un aquelarre del siglo $\mathrm{X}$ y para los pueblos nahualts precolombinos. La cultura determina comunidades con usos y costumbres diferentes. La vida de un melómano amante de Bach es diferente de quien se declara amante de Chavela Vargas o del jazz norteamericano de la primera mitad del siglo XX. Análoga consideración podríamos hacer, desde Cassirer, si comparamos a un católico y un protestante en la época de la Reforma o a un médico homeópata y un alópata (en el marco de la ciencia).

Desde aquí, se añade a la consideración beuchotiana que el símbolo une a los propios, pero también separa de los ajenos.

Retomando el plano religioso, resulta elocuente recordar el citado delirio persecutorio aludido por Zambrano (1993) en El hombre y lo divino (p. 31). Previo a la separación con el mundo, el hombre (el poeta) se sentía inmerso en el mundo y bajo el poder de fuerzas que le superaban. Sentía la persecución de la realidad de la 
que no podía escapar. Esa persecución fragua comunidades que se reúnen para minimizar sus efectos negativos (por las oraciones, por ejemplo) y, desde la óptica del gozo religioso de la bonanza escanciada por los dioses, para disfrutar del poder de los entes superiores.

\section{II.D. SÍMBOLO, SER Y ESPÍRITU}

La unidad social o grupal propiciada por el símbolo emana de la posesión de un espíritu compartido. Los miembros se unen por la entrada en un universo que trasciende las fronteras espacio-temporales de cada uno de ellos. El alma de los mitos aludida por Eliade, lo originario señalado por Ricoeur, el objeto perseguidor de Zambrano o esa entraña que no es totalmente explícita en Beuchot se aclaran cuando nos apercibimos de que la interpelación ricoeuriana es ejercida por el espíritu o el ser de la realidad llamando a sí mismo. María Zambrano (2007) ha identificado esta llamada con la vocación (p. 101-120).

La vocación es el clamor del ser emplazando a la realización plena y específica de cada sujeto (p. 103-104); por tanto, cerrar los oídos a su petición incapacita a la persona a alcanzar su ser. La aceptación de la vocación no implica una construcción metafísica que separe del resto de los seres debido a que cada llamada es diferente, sino que conecta a todos los sujetos gracias a la autenticidad y cercanía con el ser.

De modo concreto, la vocación médica vertebra la capacidad curativa del ser, la vocación amorosa articula el espíritu unitivo y la vocación religiosa, el espíritu de religación con el todo. Cuando cada una de estas modalidades se materializa, el sujeto aparece como símbolo ontológico, porque su quehacer como médico (signo) posee un significante trascendente y trascendental: el ente abierto a lo sanador o curativo, al amor o a la religión.

El hombre hecho símbolo funciona como arquetipo ontológico como en el caso del arte. Escanciado el símbolo, indicará Eliade, desnuda las modalidades más secretas del ser (Eliade, 1979, p. 13) y atrae los "modelos ejemplares" a partir de los que se construye la sociedad.

Volviendo a lo anterior los modelos ejemplares aparecen en arte (o en la vida hecha arte): Romeo y Julieta no es la crónica de un desafuero amoroso infortunado sino el prototipo de los amores imposibles, El grito de Munch es la idea (en el sentido platónico) de la angustia y la Carmina Burana de Orff muestra la pauta de la épica hecha música en la contemporaneidad. Todos ellos exceden a su materialización espacio-temporal en papeles, lienzos o pentagramas. De ahí, no solo su elevado precio sino la imposibilidad de establecerlo en la mayor parte de las ocasiones: el mundo no es el mismo desde que hicieron acto de aparición en la tierra y algo cae con ellos después de su destrucción, ya que acabada la base material sobre la que descansan (libros, lienzos, partituras) es posible que se olvide la trascendentalidad que significan. Comprar el Discóbolo de Mirón es poseer un molde desde el que se ha construido la cultura de Occidente y ¿cuánto vale un mundo? 


\section{José Barrientos Rastrojo}

Beuchot (2004a, p. 19-29) y Eliade (1979, p. 12-17) describen un tercer ente simbólico espiritual: el inconsciente. Los síndromes freudianos como el de Edipo o Electra responden a esquemas pautados reiteradamente. La realidad (patológica) descansa en los moldes representados en figuras de la poesía griega. Estas realidades inconscientes no pertenecen a la psique de la persona sino que, en la medida en que el símbolo posee un anclaje ontológico-trascendental, los síndromes galopan desde el ser del sujeto. Por esta razón, el terapeuta nunca pretenderá exiliarlos del sujeto, debido a que implicaría eliminar el ser de la persona, sino integrarlos en el paciente. El síntoma enfermizo no resulta del síndrome sino de la negación u ocultación inconsciente de la persona. En este sentido, resulta interesante cómo Durand (1968) explicita que la única enfermedad del sujeto no es ostentar entidades simbólicoinconscientes sino la incapacidad para simbolizar (p. 130-131).

Desde esta circunvolución, ha de conceptuarse la vinculación entre psicoanálisis y hermenéutica: la terapia del psicoanalista no es más que una hermenéutica concienciadora. Ahora bien, esa hermenéutica no implica una explicación de la enfermedad sino una ex-posición de su naturaleza oculta, esto es, fomentar el reconocimiento por parte del paciente sea como lo indicó más arriba Ricoeur o como lo refiere Ferraris al materializar la hermenéutica como "proferir" o "decir" (Palmer, 2002, p. 31-38). Este itinerario muestra un sendero para la recuperación simbólica y la salvación del individuo: su explicitación quedará para otro trabajo.

\section{II.E. CONCLUSIÓN: SOTERIOLOGÍA SIMBÓLICA}

En síntesis, la captación simbólica de lo real traslada a la captación completa de lo real, esto es, la mencionada bipolaridad. Por el contrario, la dilapidación de esta conduce, en primera instancia, a talar una parte de lo real, la trascendental (Beuchot) $\mathrm{y}$, en un segundo momento, a silenciar y mutilar el auténtico ser del objeto, aquel que el mismo afirma ser (Heidegger). Esta tala posee consecuencias a nivel ontológico cuando se refiere a los objetos y antropológicos cuando se derrumba la potencialidad de desarrollo simbólico de la persona.

Descendiendo a lo concreto, el extravío de las dimensiones simbólicas transforma una obra de arte en una lona sobre la que se impriman sustancias cromáticas, una sinfonía que nos descubre el sentido de la amistad universal acaba en un entre-tenimiento "bonito" y degradado respecto de la voz del científico positivista que es caracterizado como el único ostentador de la verdad y, en suma, el desplome de nuestro concepto incapacita al ser humano a trascender la verdad por adecuación y a rozar la verdad ontológica; recuérdese que, siguiendo a Zambrano, esta última le guiaba a su propia vocación, a su legítimo destino y a su ser genuino.

Con todo esto, no solo se pierde parte de la realidad sino que nos perdemos a nosotros mismos. Beuchot y Norbert Elías concuerdan en que el símbolo da cumplimiento a una característica que nos diferencia de los animales: la necesidad de orientarnos. Aquellos seres que poseen su vida definida desde el nacimiento no tienen 
que lanzarse a buscarla; esto no ocurre en el ser humano: la persona se encuentra encadenado a la máxima machadiana "caminante no hay camino, se hace camino al andar". Si el ser humano queda en la inmanencia ajena al símbolo, caerá en una enfermedad mortal al incapacitarse para desarrollar su ser (Durand, 1968, p. 124140). La interpelación del símbolo es el modelo al que aspirar, la atalaya que anhelar sin hacerse excesivamente elevados para renunciar gracias a su raigambre física.

En suma, el extravío del símbolo no es una pérdida análoga a la de cualquier otro ente sino que inicia la debacle humana, primero, en lo personal y, luego, como vimos en lo social: [El símbolo] es lo que aleja la angustia, disminuye la depresión, porque hace presente el afecto, conecta con las personas. Con ello, también el símbolo es lo que da sentido, lo que señala el camino, lo que aporta una esperanza (Beuchot, 2011, p. 87).

Es tiempo de regresar a nuestra pregunta inicial para materializar la teoría: realmente, ¿se está extraviando el símbolo o asistimos a un desplazamiento sutil de su naturaleza material?

\section{DE LA ESTÉTICA COSMÉTICA A LOS ENTES SIMBÓLICOS}

\section{III.A. ESTÉTICA COSMÉTICA VERSUS ESTÉTICA ONTOLÓGICA}

La definición de "cosmética" dada por el Diccionario de la Real Academia Española incardina esta profesión en la aplicación de productos para la higiene o belleza del cuerpo. Sus especialistas se dedican a administrar sustancias que reduzcan los efectos del tiempo sobre el cuerpo y a ocultar aquellas características que no responden al modelo de belleza en curso. Así, su misión se dedica a ocultar parte de la verdad profunda (las arrugas, los defectos dérmicos) mediante un juego con la superficie.

Esta adjetivación cosmética ha coloreado la estética contemporánea y ha desplazado la vocación ontológica o la proclividad del arte a la verdad. Según Arte y verdad en la palabra, de Gadamer, esta estética cosmética responde al contenido de lo "cursi". Lo cursi es un exceso de ornato que desplaza la capacidad del pintor para generar las formas simbólicas que construye los moldes ideales de la vida. De acuerdo con Gadamer, la tendencia poliniza todos los universos: "Esto afecta también, obviamente, a los casos en que formas del decir poético tomadas exteriormente son puestas al servicio de contenidos que no están legitimados bajo el punto de vista del arte, sino por intereses de otra especie. Piénsese en la cursilería religiosa o patriótica" (Gadamer, 1988, p. 72).

Un nivel menos devaluado de la estética lo encontramos en la "moda". La "moda" corresponde con el gusto de una determinada época, o de un conjunto de personas, pero sigue olvidando que el arquetipo sea ontológico, trascendental, es decir, la verdad antes que el gusto estético ideologizado y manipulado.

Por último, el "estilo" sería aquel que se acercaría más a la verdad, pues trasciende toda la restricción del gusto espacio-temporal, si bien una persona con 


\section{José Barrientos Rastrojo}

estilo pueda adaptarse a cada escenario cultural (Gadamer, 2001, p. 69-70) y ser valorada por la comunidad por su gusto.

La extensión de la devaluación ontológica del arte en lo "cursi" y la "moda" son síntomas de la pérdida de las dimensiones trascendentales en que ha incursionado la estética. Ambas categorías han aherrojado la estética en dimensiones sociales, psicológicas y circunscritas a un contexto específico. Así, la estética no respondería a una verdad trascendental sino al reductor gusto social o, agravando el asunto, muestra débitos profundos con intereses económicos y con los sectores poderosos.

La desaparición de las dimensiones veritativas de la estética constituye el punto de partida de la crítica gadameriana de Verdad y método. Sin embargo, lo animan a recuperar esa verdad eclipsada para escapar del modelo de adecuación, más propio de las coyunturas modernas.

Análogamente a la estética, el símbolo se ha teñido de los tintes modernistas que lo distinguen como una construcción humana particular, antes que como una verdad a la que pertenece quien lo contempla o escucha, contextual $y$, a veces, caprichosa. Aquí, se alojan aquellos comentarios que señalan que un buda sedente posee un significado exclusivamente para los budistas, que un icono ortodoxo solo debe ser respetado por quienes practican aquella religión o los que señalan que el valor de un libro pertenece a aquel que se lo confiere, pero no pertenece realmente al libro, porque que son creaciones de esas culturas sin ser conscientes de que el símbolo no pertenece al hombre sino todo lo contrario. El esquema se infiere del modelo moderno y cartesiano de entender la subjetividad: la res extensa es deudora (e hija) de la res cogitans (de la psique o del yo). Dentro de este marco, la realidad cognoscible se abre como el fenómeno pero nunca el noúmeno, esto es, el objeto de conocimiento se entiende siempre como una re-presentación de la vida, pero nunca la vida misma. Esa representación supone siempre un objeto mediado por condiciones apriorísticas humanas, las celebérrimas kantianas.

Autores como Zambrano, Heidegger, Gadamer o Panikkar critican el egocentrismo cartesiano y kantiano y advierten acerca de la soberbia de un sujeto que se ha erguido como dios de lo que le rodea: la limitación espacial humana impide considerar que el ser humano sea capaz de crear el arte, el lenguaje o la religión. Estos orbes son excesivamente amplios para su reducido campo de acción. Por el contrario, el individuo se debería considerar como una herramienta (con cierta capacidad de decisión) que presta su voz, manos y mente para que, por su intermedio, estas se expresen. No somos nosotros quienes creamos el mundo sino que este nos utiliza para materializarse en nosotros: una conferencia memorable no es resultado de la grandeza creativa de quien ha hablado sino del espíritu que usó a esa persona para concretarse. "El comprender debe pensarse menos como una acción de la subjetividad que como un desplazarse uno mismo hacia un acontecer de la tradición, en el que el pasado y el presente se hallan en continua mediación" (Gadamer, 2001, p. 360). Tan afortunado es el espectador de tal alocución como quien la expone por haber sido agraciado por 
esa posibilidad. Considerar que el éxito es exclusivamente personal es caer en la soberbia de creer que somos los únicos productores de esa posibilidad inédita. Si así fuese, ¿qué impediría volver a repetir el éxito en todas las circunstancias? Esto no quiere decir que la persona no tenga algo que ver en el proceso, pues la probabilidad de éxito vaya aumentando a medida que su experiencia es mayor. Ahora bien, ¿no se debe acaso su éxito a estar abierto a esa inspiración graciosa más que a una creación de un ser cuya vida no es más que una fracción de segundo en la existencia del universo?

Este planteamiento se infiltra en nuestro tema focal. El moderno conceptúa el símbolo como creación psicológica individual, como algo que surge de las manos de una persona o de un grupo, esqueleto que repite el de las botas conceptuadas como ente de uso para el labriego. La propuesta gadameriana es la inversa: el símbolo crea al creyente y descubre al buscador su esencia: la mirada de profunda nostalgia de Domínguez Bécquer del retrato de su hermano enseña un modelo de ser al que muchos aspirarán.

En consecuencia, la función del que se acerca al símbolo no es crearlo sino cantarlo, revivificarlo y proclamarlo pero no diseñarlo, como decíamos, el sujeto pertenece al símbolo y no viceversa.

El descubrimiento de la vida propia del símbolo, del metal no es propio de la estética cosmética, ya que su finalidad no es entre-tener y crear gozo hedonista, es decir, tener en un entre solazado, sino descubrir verdades paradigmáticas que no aparecen en el trasiego cotidiano. Así, la obra de arte no es cosmética; ítem más: solo es estética en la medida en que hace emerger el ser constreñido en su forma, es decir, hace emerger su verdad, su forma simbólica. Se trata de la unificación de dos de los tres trascendentales medievales, verum y pulchrum, que devuelven al arte su periclitada entidad a instancias de una tendencia cogitante absolutista humana.

En síntesis, no solo se llena de sentido la estética con la verdad sino que se supera una postura esteticista cosmética donde su valor se hacía descansar en una superficie nihilista inmoderada: en la medida en que se afirmaba que lo crucial era la epidermis bella, la estética se hacía raquítico tema de "florecillas burguesas". Hay que dejar que el vigor rilkeano del "florecer porque florece" arrase con aquellas margaritas puestas al servicio de un cursi "me-quiere-no-me-quiere".

\section{III.B. ENTES SIMBÓLICOS ALLENDE LA RELIGIÓN}

El discurso anterior trasladado al símbolo explica los dos peligros que se deslizan en los ritos actuales: esteticismo cosmético y vacío ontológico-veritativo nihilista.

Según Mauricio Beuchot, el exilio de los entes simbólicos es patente en la desaparición (o disminución) de estos en la religión o la salida de escena de esta del orbe social. Sin embargo, consideramos más relevante que discutir sobre las evidencias estadísticas que cohonesten o refuten esta aseveración, reflexionar acerca 


\section{José Barrientos Rastrojo}

de la influencia persecutoria que estos poseen en el no creyente con el fin de averiguar si son posibles aun en mundos laicos.

Durante el medievo europeo, el símbolo religioso poseía un efecto tanto en el creyente como en el heterodoxo. Ambos percibían su poder de la realidad, con un sentido opuesto en cada grupo: sumisión o reivindicación beligerante. La cruz poseía una influencia en el cristiano con un poder que era idénticamente defendido por los miembros de los aquelarres que podían usarlo para fines siniestros (a ojos de la Iglesia instituida). Ambos sectores percibían la íntima unidad entre la parte física del símbolo y la trascendental así, no había oposición a su dominio ontológico sino en relación a los modos de utilizarlo.

En la contemporaneidad, solo el creyente asume la potestad simbólica. Aparece una nueva figura en este campo, el agnóstico, que se une al creyente y al ateo o al ortodoxo y el heterodoxo. El agnosticismo implica una indiferencia respecto de una realidad simbólica que, en su imaginario, solo posee la parte metonímica o física. Por tanto, no solo no comparten ninguna de los sentidos citados (a favor (+) o en contra (-)) sino que se alejan de la dirección (no les importa la religión). Estos sujetos se adhieren a la consideración modernista y circunscriben la base trascendental del símbolo a la cogitación (creación), psicologización o creencia de un sujeto o grupo, sin que esta se aflore por sí misma del objeto. Admiten que existe el vuelo, pero niegan que proceda del universo del objeto, por el contrario, parte de la psicología o las creencias diseñadas por el individuo.

Regresemos a nuestra pregunta inicial: ¿existen seres simbólicos o estos decaen?, ¿Beuchot o Eliade? Desde nuestra perspectiva, ambos tienen razón. Por una parte, la devaluación de ciertas religiones, el laicismo en algunas sociedades y la incursión de diversos universos religiosos o ideológicos en la sociedad global provoca que sus entrañas simbólicas desaparezcan. Ahora bien, la destrucción de las instancias simbólicas clásicas (incluidas en la religión), ¿destruye todos los símbolos? La pujanza de la lectura de libros históricos, el amor a la bandera de grupos profesionales o de sociedades nacionalistas, la adhesión a ideales de jugadores de fútbol o cantantes pop, la admiración por grandes creadores de las nuevas tecnologías o por artistas de cine serían razón suficiente para demostrar que el símbolo permanece.

Algunos críticos se quejarían de que tales entidades no serían símbolos, pues, en última instancia, su capacidad trascendental se vulnera en una inmanencia objetual (el cantante, la película, el actor o el futbolista). A estos críticos podría indicárseles que echen una ojeada a los modelos de racionalidad moderna frente a los contemporáneos y que trasladen las características de una y otra al campo simbólico. El hecho de que la razón hoy no pueda absolutizarse o universalizarse como pretendió la modernidad, ¿es razón suficiente para decir que modelos más modestos de racionalidad no pertenecen a la razón? Hoy, se yerguen modelos de racionalidad y de metafísicas (líquidas, analógicas, reticulares, contextuales, etc...) alternativos que no son negados por gran parte de la comunidad científica y de pensadores. 
Ahora bien, la limitación inmanente de estos nuevos símbolos contemporáneos (que serían idolátricos en el pasado) ¿rompe con las características simbólicas citadas en los apartados anteriores? Consideramos que no es así, porque en ningún momento se indicó la altura a la que debe alzar el vuelo metafórico, la necesidad de que el número de miembros de la sociedad que une el símbolo sea toda la humanidad o si el espíritu que ex-pone y expresa ha de ser único para todas las etapas de la persona. Buscar esta unicidad metatemporal-espacial, ¿no sería acaso fruto del prejuicio ilustrado que criticase Gadamer en su obra? (Gadamer, 2001, p. 337).

Quizás el cantante pop erosione su imagen con el paso del tiempo, pero su condición simbólica no solo procede del carácter metonímico, aquel que queda lastimado, sino también de su condición trascendental. Por eso se le invita a programas televisivos aun cuando su mirada y brío dista mucho del arquetipo al que aspiraban los fans. De hecho, esa condición trascendental es la que se valora y no la metonimia desgastada por la edad: el simbolismo de cierto jugador de fútbol requiere para brillar un asiento físico concreto, pues lo trascendental no es posible verse sin su incardinación en un espacio y un tiempo; ahora bien, su rutilancia es resultado del hecho de cómo esa materialidad (potencia) se convierte en acto. Así, su naturaleza simbólica no reside en las piernas sino en la jugada maestra irrepetible que se convierte en arquetipo para otros jugadores. Estas jugadas engarzadas constituyen un ente simbólico, singularizado en el jugador de fútbol. Ésta totalidad inédita es el símbolo y no el jugador específico. Como el crucifijo, el jugador se deteriorará, pero respondiendo al crítico ilustrado, ¿acaso el simbolismo de Pelé, Maradona o Messi no reside en sus jugadas y escapa no solo con la edad sino con los momentos de lesiones?

\section{III.C. TIEMPOS Y ESPACIOS SIMBÓLICOS}

La desaparición de los tiempos simbólicos, los días festivos, y su determinación mediante el consenso nos trae nuevamente a la cuestión.

En ciertos países, los días festivos fueron en el pasado conmemoración simbólica de circunstancias que perfora la consideración cronológica del tiempo desde una adjetivación kairótica. Esas fechas señaladas asistían a conmemoraciones donde se recordaba lo vivido o, desde contextos religiosos, se volvía a vivir lo acontecido como si ciertos hechos no pertenecieran a un año específico sino que hubieran teñido ese día del año o de la semana de modo particular. Casos paradigmáticos son la celebración del domingo como día dedicado a Dios por los católicos, el shabat de los judíos, el ramadán de los islámicos, la celebración del día de la comunidad autónoma o el día del padre.

Resultan llamativos dos desplazamientos en el tiempo simbólico. Primero, los nuevos días simbólicos institucionalizados tienden a establecerse como reivindicación más que como celebración sagrada: el día de la mujer trabajadora no conmemora algo existido sino que exige algo no instituido: demanda una ausencia antes de celebrar una presencia temporal. Asimismo, el día de la filosofía recuerda la necesidad de que esta 


\section{José Barrientos Rastrojo}

disciplina recupere un lugar destacado para no caer en las consecuencias de su ausencia, el día contra el cáncer de mama o contra el SIDA no solemniza sus contenidos sino que son útiles para la lucha contra estas lacras patológicas. Esta deriva subraya el movimiento citado más arriba: el sujeto no se introduce en estos tiempos bajo la persecución sagrada de los días, por el contrario, la persona alza sus armas para construir desde sus propios poderes algo que no existe.

En segundo lugar, la teoría de la acción comunicativa habermasiana (Habermas, 1999), las racionalidades dialógicas, el consenso como forma de comprensión en el seno de metarrelatos dispares, las instauración de modelos democráticos sobre los teocráticos y la comprensión no ontológica del símbolo conduce al establecimiento de festivos por convenios entre los diferentes intervinientes. De esta forma, la justificación de la festividad no se arrellana en la raíz ontológica sino en el acuerdo entre las diversas partes. Nuevamente, el esquema olvida quedar a la escucha del tiempo para que sea este el que explique el valor del día y desde esta actitud se determine el momento más adecuado (más sagrado) para la celebración sino que el sujeto determina racionalmente la mejor fecha basándose en la utilidad o funcionalidad.

La quiebra del valor ontológico se patentiza en las valoraciones resultantes de los espectadores del símbolo, pues como indicamos, el agnóstico constata que el rito es resultado de un acuerdo social y olvidan la base ontológico-metafórica en la que se enraíza. De hecho, en la medida en que el tiempo se establece por este contrato social se disuelve el valor simbólico, ya que no se clausura la metafísica metafórica. Solo cuando tal asociación se disipa, el tiempo simbólico pierde fuerza. Si se decide trasladarse una festividad al día siguiente o al anterior "por comodidad", se incursiona en un utilitarismo que aniquila al símbolo, porque la verdad que debe expresar el símbolo desaparece.

Las reflexiones acerca de los espacios simbólicos concuerdan con este modelo. El espacio simbólico por antonomasia es el templo. La mezquita, la iglesia o el templo maya exigen una disposición para cruzar su umbral. Los comportamientos de sus moradores se diferencian a los ejecutados en el espacio profano. Su división responde a modelos cosmológicos y cualitativos antes que cuantitativos, es decir, hay espacios más sagrados que otros. Las consecuencias citadas más arriba se repiten en estos espacios y son elocuentes en aquellos turistas que visitan catedrales, a causa de que olvidan el valor simbólico y se quedan en el artístico-histórico.

Esto no debe conducirnos a pensar que los espacios simbólicos se han destruido. Por el contrario, muchos de los pasados se han mantenido y han aparecido otros nuevos: repárese en cuáles fueron los objetivos terroristas en Nueva York hace algunos años y en la razón de tal elección. Se puede pensar que con el intento de destrucción de la Casa Blanca o del Pentágono se respondía a un utilitarismo político (matar al Presidente); sin embargo, las informaciones coincidían que la caída de las Torres Gemelas pretendía una misión hermenéutica universal: la devastación simbólica del poder occidental sobre 
Oriente. Análogas consecuencias se extraen si se hubiera destruido el centro económico de Wall Street, templo financiero occidental por excelencia.

\section{CONCLUSIÓN}

Comenzamos este trabajo con una pregunta cuya respuesta parecía responderse con sencillez visto desde la perspectiva estadística: si se desea saber si las realidades simbólicas están desapareciendo solo es preciso cotejar el pasado con el presente y evidenciar su disminución. Sin embargo, esta fue la excusa para, como suele hacer la filosofía, cuestionar la propia inquisición y extraer una verdad que descansa en su seno.

Entender la desaparición del símbolo exige conocer qué es un símbolo indagando para ello en sus características. Estas dimensiones abrieron la posibilidad de que la pregunta se optimizase: el nudo gordiano no descansaba tanto en si los entes simbólicos desaparecían o se desplazaban sino si aquello que podía entenderse como símbolo en la realidad descansaba en la función simbólica.

Para ello tuvimos que escindir entre las concreciones simbólicas y el simbolismo como función. De esta forma nos apercibimos que este posee diversos rostros. Cada uno de esos rostros coincide con el magma filosófico de cada época, siendo muy diferente el estatismo ontológico y gnoseológico del pasado aplicado a nuestro concepto y la multiformidad cromática de la contemporaneidad. Sin duda, capturar el símbolo en la evanescencia contemporánea requiere una gimnástica innecesaria en otras épocas e incluso insertase en la posibilidad de que este sea una función antes que un ente (tema que abordamos en una investigación que se publicará en breve). No obstante, mantenerse una visión periclitada en relación con el símbolo podría llevar a no conseguir captar los nuevos entes simbólicos ni sus dinámicas contextuales actuales.

Esta nueva flexibilidad simbólica exige una categorización diferente que nos permita comprender al símbolo sin renunciar a él: acceder al símbolo como función moldeadora de la realidad antes que como realidad dada, es decir, detenernos más en el simbolismo o la simbolización que en el objeto mismo. Esta premisa jalona el segundo bloque de nuestro trabajo y es la razón por la que, en lugar de detenernos en definiciones acerca del símbolo, buceamos en sus características definitorias.

Nuestro trayecto no responde la cuestión sino que la disuelve: no se pretende descubrir la existencia de símbolos en la actualidad sino de advertir que tal cuestión periclita a la luz de los contextos contemporáneos y de las nuevas realidades simbólicas. Ni qué decir tiene que este itinerario, a pesar de invalidar la cuestión, nos devuelve otra: ¿hemos de mantener la carta de ciudadanía de la simbolización entendida como función ontológico-veritativa?, ¿es posible seguir generando símbolos o seguirlos captando? A la luz de lo visto, el lector entenderá que la única respuesta es la rotundidad de la aquiescencia. Ahora bien, esta rotundidad no está dada sino que es preciso construirla. Esta construcción ha de saltar por encima de la edificación humanista de la modernidad para descender al modelo contemporáneo de la escucha y del canto. El significado del símbolo no es una creación individualista o una fantasía de iluminados de los que se 
aparta la seriedad positivista sino una verdad que permanece aun a los sordos y ciegos que le dan la espalda. Esto último implica que el símbolo no posee potencia impositiva sino interpeladora, como apuntaba Ricoeur, lo que provoca que se precisa estar atento al mismo, crear un silencio (Panikkar, 2001, p. 43-44) para entrar en su universo trascendente.

La aprehensión del significado simbólico es un descubrimiento personal basado en la capacidad de sugestión de este y en la disposición humilde del contemplador. Aun así, se puede ayudar al otro a que lo intuya. Las formas de concretar esto son el canto y el profetismo hermenéutico... pero esto pertenece a otra investigación.

Universidad de Sevilla* Facultad de Filosofia Departamento de Metafisica y Corrientes actuales de la Filosofia, Ética y Filosofia Política Calle Camilo José Cela s/n. 41018, Sevilla (España) barrientos@us.es

\section{OBRAS CITADAS}

Beuchot, Mauricio. (2011). Metáforas de nuestra vida. Antropología e interpretación. Huelva: Hergué.

— (2007). Hermenéutica analógica, símbolo, mito y filosofia. México DF: UNAM.

—_ (2004a). Antropología filosófica. Hacia un personalismo analógico-icónico. Madrid: Enmanuel Mounier.

— (2004b). Filosofia política. México DF: Torres Asociados.

— (1999). Las caras del símbolo. El icono y el ídolo. Madrid: Caparrós.

Cassirer, Ernst. (1967). Antropología filosófica. Introducción a la filosofia de la cultura. México: Fondo de Cultura Económica.

_ (1971). Filosofia de las formas simbólicas I. El lenguaje. México: Fondo de Cultura Económica.

Conill, Jesús. (1991). El enigma del animal fantástico. Madrid: Tecnos.

Durand, Gilbert. (1968). La imaginación simbólica. Buenos Aires: Amorrortu.

Eliade, Mircea. (2011a). Historia de las creencias y las ideas religiosas: Volumen II: De Gautama Buda al triunfo del cristianismo. Barcelona: Paidós.

— (2011b). Historia de las creencias y las ideas religiosas: Volumen III: De Mahoma a la era de las Reformas. Barcelona: Paidós.

— (2010). Historia de las creencias y las ideas religiosas: Volumen I: De la edad de piedra a los misterios de Eleusis. Barcelona: Paidós.

— (1996). Historia de las creencias y las ideas religiosas: Volumen IV: Desde la época de los descubrimientos hasta nuestros días. Barcelona: Herder.

_ (1979). Imagens e símbolos. Lisboa: Arcádia-Minerva. 
Elias, Norbert. (1994). Teoría del símbolo. Un ensayo de antropología cultural. Barcelona: Península.

Gadamer, Hans G. (2001). Verdad y método I. Salamanca: Sígueme.

- (1988). Arte y verdad en la palabra. Barcelona: Paidós.

Habermas, Jürgen. (1999). Teoría de la acción comunicativa. Volumen I. Madrid: Taurus.

Heidegger, Martin. (2001). Caminos del bosque. Madrid: Alianza.

Machado, Antonio. (1997). Campos de Castilla. Barcelona: Rincón Castellano.

Marí, A. (1988) "De divina inspiratione" en Marí, A. et al. Premio "Miguel de Cervantes". Barcelona: Anthropos.

Panikkar, Raimon. (2001). Iconos del misterio. La experiencia de Dios. Barcelona: Península.

Palmer, Richard. (2002). ¿Qué es la hermenéutica? Teoría de la interpretación en Schleiermacher, Dilthey, Heidegger y Gadamer. Madrid: Arcolibros.

Ricoeur, Paul. (2004). Finitud y culpabilidad. Madrid: Trotta.

Zambrano, María. (2007). Filosofia y educación. Málaga: Ágora.

— (2004). De la aurora. Madrid: Tabla Rasa.

— (1993). El hombre y lo divino. Madrid: Fondo de Cultura Económica. 